УДК 556.3, 556.314

\title{
ГИДРОГЕОЛОГИЧЕСКИЕ УСЛОВИЯ НАРЫКСКО-ОСТАШКИНСКОЙ ПЛОЩАДИ ЕРУНАКОВСКОГО РАЙОНА КУЗБАССА
}

\author{
Домрочева Евгения Витальевна',
}

DomrochevaYV@ipgg.sbras.ru

Кузеванов Константин Иванович², kki@tpu.ru

Гридасов Александр Геннадьевич², gridasov@tpu.ru

\author{
Сизиков Дмитрий Александрович', \\ D.Sizikov@promgaz.gazprom.ru \\ 1 Томский филиал Института нефтегазовой геологии и геофизики им. А.А. Трофимука СО РАН, \\ Россия, 634055, г. Томск, пр. Академический, 4. \\ 2 Национальный исследовательский Томский политехнический университет, \\ Россия, 634050, г. Томск, пр. Ленина, 30. \\ ${ }^{3}$ Научно-технический центр «Освоение нетрадиционных ресурсов углеводородов», \\ Россия, 117420, г. Москва, ул. Наметкина, 6.
}

Актуальность работы обусловлена необходимостью изучения состава подземных вод и гидродинамических условий Нарыкско-Осташкинской площади Кузбасса, перспективной для добычи угольного метана.

Цель работы: охарактеризовать гидродинамические условия и гидрогеохимические особенности Нарыкско-Осташкинской площади, а также описать условия питания и разгрузки подземных вод для схематизации гидрогеологических условий района разведочных работ на угольный метан.

Методы. Химический состав подземных и поверхностных вод исследовался в Проблемной научно-исследовательской гидрогеохимической лаборатории (ТПУ), зарегистрированной в Системе аналитических лабораторий Госстандарта России. Для проведения полного химического анализа использовались традиционные методы. Обработка опытно-фильтрационных работ выполнена по стандартной методике графоаналитического метода временного прослеживания уровня с последующими графическими построениями и вычислениями, выполненными в среде программном комплекса MS Office.

Результаты выполненных исследований позволяют уточнить некоторые особенности гидрогеологических условий НарыкскоОсташкинской площади. Так, по итогам опытно-фильтрационных работ в устье реки Осиновка установлено наличие гидравлической связи подземных вод верхней гидродинамической зоны с поверхностными водотоками, а также определены значения коэффициентов водопроводимости и уровнепроводности для этой части гидрогеологического разреза. На основе оценки взаимодействия подземных и поверхностных вод по результатам опытно-фильтрационных работ установлено наличие выраженного влияния граничных условий I и III рода на работу гидрогеологических скважин, что позволяет существенно актуализировать гидродинамические модели, которые могут быть использованы для обоснования добычи угольного метана в этом районе. Кроме этого, выяснено, что в пределах массивов слаботрещиноватых пород существуют изолированные напорные системы, формирование которых обусловлено наличием в разрезе прослоев с невысокой водопроводимостью. По характеру проницаемости в гидрогеологическом разрезе выделяются зоны интенсивного и замедленного водообмена. В гидрогеохимическом отношении с ними коррелируют зоны пресных и солоноватых вод.

\section{Ключевые слова:}

Подземные воды, Кузбасс, Нарыкско-Осташкинская площадь, химический состав, генезис вод, гидродинамические условия.

\section{Введение}

В настоящее время территория Ерунаковского района активно изучается в рамках проекта по освоению нетрадиционных ресурсов метана из угольных пластов и характеризуется существенными геологическими и технологическими рисками, которые особенно значимы на ранних стадиях. $[1,2]$. В связи с этим изучение гидрогеологических условий имеет высокую актуальность, т. к. полученные данные будут востребованы при проектировании промышленной добычи угольного метана. Региональные гидрогеологические особенности этого района описаны нами ранее в журнале
«Геология и геофизика» и др. [3-8], а геохимические - в журнале «Известия ТПУ " [9-12]. Несмотря на интенсивное освоение территории, по-прежнему вызывает трудности её низкая гидрогеологическая изученность, выраженная в недостатке гидродинамических и гидрогеохимических наблюдений и опробований.

Проблема изученности подземных вод угленосных отложений в последнее время всё чаще освещается не только в России $[1-8,10,13-16]$, но и в зарубежных изданиях [17-31], что связано с повышением интереса $\mathrm{\kappa}$ освоению ресурсов угольного метана в различных странах. Наибольший опыт в 
данной сфере накоплен в США [27-29], Польше [22] и Австралии [20]. Активно развиваются в этой связи исследования подземных вод угольных бассейнов Китая [18, 19, 21-26].

\section{Фактический материал и методы исследования}

Томский филиал ИНГГ СО РАН, начиная с 2002 г., ведет совместные работы с 000 «Газпром добыча Кузнецк» по изучению гидрогеологии, гидрогеохимии и экологии территорий потенциальной промышленной добычи угольного метана в Кузбассе. В 2012 и 2014 гг. наши исследования были сосредоточены на территории Нарыкско-Осташкинской площади Ерунаковского района Кемеровской области, являющейся одной из приоритетных площадей для крупномасштабной добычи угольного метана. С 2009 по 2012 гг. здесь пробурили 41 скважину глубиной от 100 до $1200 \mathrm{M}$, откуда отбирали пробы воды [9]. В 2014 г. было отобрано дополнительно 12 проб на этой территории из глубоких горизонтов. Таким образом, гидрогеохимические условия района анализировались по 124 пробам из 41 скважины (рис. 1).

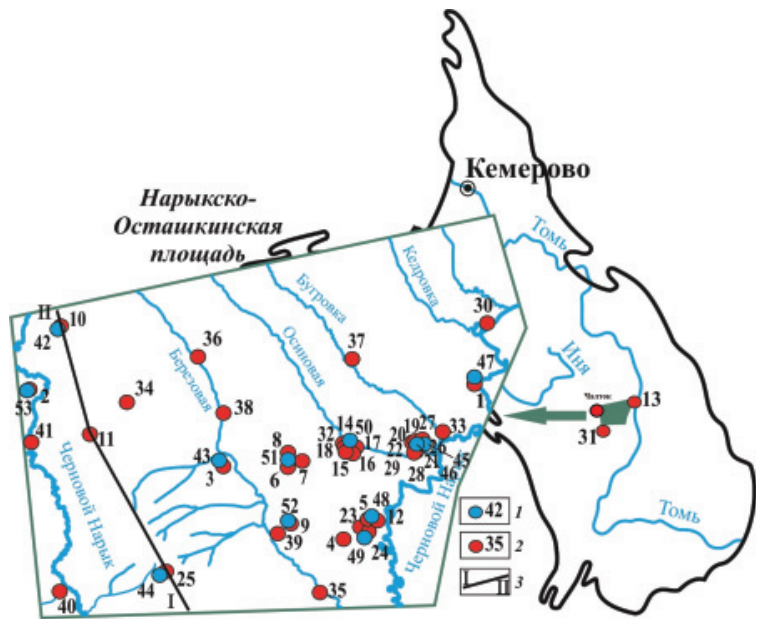

Рис. 1. Обзорная схема отбора проб воды: номер отобранной пробы 1 - в 2014 г.; 2) в период с 2009 по 2013 гг.

Fig. 1. Overview water sampling scheme: sample number 1-in 2014; 2) in the period from 2009 to 2013

В каждой точке гидрогеохимического опробования непосредственно на месте отбора определялись параметры быстроизменяющихся компонентов и свойств, таких как $\mathrm{Eh}, \mathrm{pH}$, температура, ионы $\mathrm{NO}_{2}^{-}, \mathrm{NO}_{3}^{-}, \mathrm{NH}_{4}^{+}, \mathrm{Fe}^{2+}$ и $\mathrm{Fe}^{3+}$. Макрокомпонентный и микрокомпонентный состав вод исследовались в Проблемной научно-исследовательской гидрогеохимической лаборатории Томского политехнического университета, зарегистрированной в Системе аналитических лабораторий Госстандарта России. Для проведения полного химического анализа вод использовались традиционные методы, а также методы спектрального, атомно-абсорбционного анализа и др.

Гидродинамические опробования НарыкскоОсташкинской площади проведены в период с
2012 по 2013 гг. на двух участках. В районе устья реки Осиновка выполнена кустовая откачка, при которой задействовалась одна центральная и четыре наблюдательных скважины. Глубина опробования составила 110 м. В непосредственной близости от западной границы площади, по мере бурения скважины у п. Чалток, выполнены одиночные откачки из двух изолированных толщ. Глубина опробования составила 500 м. Обработка материалов обеих откачек проводилась графоаналитическим методом прямолинейной анаморфозы на основе временного прослеживания изменений уровня в условиях длительной откачки при квазистационарном режиме фильтрации. В основу обработки результатов восстановления уровня после откачки положено представление о формировании этого процесса на основе принципа суперпозиции. В качестве основной расчётной зависимости в обоих случаях использовалось уравнение ТейсаДжейкоба. Графические построения и вычисления выполнены в программном пакете MS Office, для чего была разработана авторская полуавтоматизированная система в среде электронных таблиц Excel.

\section{Гидродинамические условия}

Нарыкско-Осташкинская площадь расположена в области расчленённого низкогорного рельефа с таёжным ландшафтом. Особенности гидродинамических условий определяются полуоткрытым характером территории под влиянием комплексного взаимодействия поверхностных и подземных вод в трещиноватой толще геологического разреза. Территория относится к бассейну реки Томь, гидрографическую сеть формирует река Черновой Нарык и его притоки. В структурном плане площадь приурочена к Кыргай-Осташкинской синклинали (южная часть) и Нарыкской антиклинали (северная часть). Структуры имеют брахиподобную вытянутую форму. В ядре синклинали залегают мезозойские отложения (триас, юра), мощность которых достигает 755 м. В антиклинальной структуре обнажаются пермские отложения ленинской свиты.

По литолого-стратиграфическим и гидродинамическим признакам в районе выделяют водоносные комплексы четвертичных аллювиальных, юрских, триасовых и пермских отложений, а также воды спорадического распространения верхнечетвертичных-современных рыхлых пород.

Ввиду особенностей литологического строения и истории геологического развития рассматриваемой территории проницаемость разреза определяется в основном степенью трещиноватости водовмещающих пород и открытостью трещин. Таким образом, наиболее проницаемым является интервал развития экзогенной трещиноватости, распространённый от кровли скальных пород до глубин 60-180 м.

Как отмечалось ранее [5, 7], для Кузнецкого бассейна в целом характерна прямая вертикаль- 
ная гидродинамическая зональность, которая прослеживается и в разрезе Нарыкско-Осташкинской площади. В зависимости от условий движения подземных вод здесь выделяют две гидродинамические зоны: интенсивного и замедленного водообмена.

Зона активного водообмена имеет мощность до 180 м на водораздельных участках и до 80 м в долинах рек. Зона приурочена к области развития экзогенной трещиноватости. Уровень подземных вод наблюдается на глубинах от 40 м на водоразделах до +6 м в долинах водотоков. Величины коэффициента фильтрации меняются от 0,3 до 1,3 м/сут. Наибольшие значения коэффициента фильтрации выявлены в угленосных породах под долинами рек, там же зафиксированы и наибольшие напоры подземных вод. Положение уровней подземных вод свидетельствует об их движении от водораздельных площадей, являющихся областями питания, к долинам рек, которые являются областями разгрузки.

Зона замедленного водообмена охватывает интервал глубин от 160 до 1300 м, возможно и глубже. В этой зоне породы характеризуются меньшей трещиноватостью, чем в зоне интенсивного водообмена, соответственно снижается проницаемость разреза и скорость водообмена. При этом в пределах зоны замедленного водообмена не наблюдается закономерного снижения проницаемости с глубиной, а хорошо проницаемые участки встречаются даже на глубинах более 1000 м [7]. Поскольку верхняя и нижняя гидродинамические зоны связаны системой трещин, их уровенный режим считается взаимозависимым. Тем не менее в скважине у п. Чалток зафиксировано существенное $(50,44 \mathrm{M})$ различие уровней смежных интервалов проницаемых пород, что свидетельствует о наличии неразрушенных слабопроницаемых прослоев в разделяющей толще. Фильтрационные характеристики разреза определяются трещиноватостью. При этом угольным пластам присуща большая проницаемость, чем смежным породам (аргиллитам, алевролитам и песчаникам), что связано со свойственной им собственной трещноватостью - кливажом.

При участии авторов в изучаемом районе проведены исследования, результаты которых позволяют существенно расширить представления об особенностях гидродинамических условий Нарыкско-Осташкинской площади.

На восточной части площади, в районе устья реки Осиновка, в 2012 г. выполнена кустовая откачка из водоносного горизонта со свободной поверхностью. В результате определены фильтрационные показатели верхней гидродинамической зоны до глубины 110 м, а также выявлена гидравлическая связь подземных вод верхней зоны с поверхностными водотоками. Коэффициент водопроводимости получен на этапе обработки результатов восстановления уровня в скважинах после откачки, его среднее значение составляет $26,7 \mathrm{~m}^{2} /$ сут. Коэффициент уровнепроводности определён по ре- зультатам обработки данных о снижении уровней подземных вод в наблюдательных скважинах во время откачки. Среднее значение коэффициента уровнепроводности составляет $4,2 \cdot 10^{4} \mathrm{M}^{2} /$ сут. Эти значения фильтрационных параметров могут быть использованы в качестве расчётных для выполнения прогнозных гидродинамических расчетов на участке исследований. Обработка графиков временного прослеживания показала, что опытнофильтрационные работы проводились в условиях взаимодействия с границей первого рода. Таким питающим контуром служит русло реки Осиновки. В силу данного обстоятельства при анализе гидрогеологических условий Нарыкско-Осташкинской площади рекомендуется учитывать тот факт, что малые поверхностные водотоки с расходами, близкими к расходу реки Осиновки и превышающие его, с большой степенью вероятности гидродинамически связаны с потоками подземных вод и должны рассматриваться как граничные условия первого или третьего рода.

Гидродинамическое опробование скважины у п. Чалток, вблизи западной границы НарыкскоОсташкинской площади, выполнено осенью 2013 г. [14]. Одиночные откачки проводились в интервалах глубин 50-200 и 200-500 м, опробования выполнены последовательно по мере проходки скважины, после тщательной изоляции вышележащих интервалов. В результате получены данные о фильтрационных свойствах и уровенном режиме опробованных толщ (таблица).

таблица. Гидродинамические показатели разреза скважины у п. Чалток

Table. Hydrodynamic parameters of the well located near Chaltok village

\begin{tabular}{|c|c|c|c|c|c|c|}
\hline 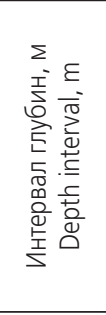 & 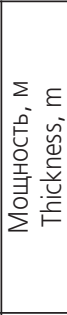 & 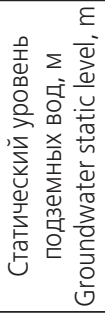 & 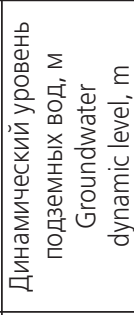 & 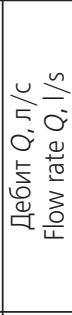 & 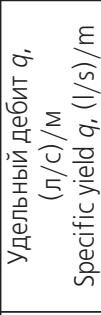 & 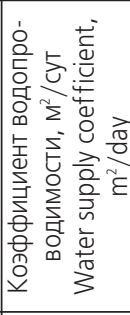 \\
\hline $50-200$ & 150 & 32,42 & 100,00 & 1,82 & 0,03 & 1,7 \\
\hline $200-500$ & 300 & 82,86 & 91,25 & 0,34 & 0,04 & 1,5 \\
\hline
\end{tabular}

Результаты опробования позволяют судить о высокой степени изоляции опробованных интервалов глубин, что предполагает возможность выявления изолированных водоносных горизонтов в толще пермских угленосных отложений. Зона замедленного водообмена в целом охарактеризована как слабопроницаемая. Существенного затухания проницаемости с глубиной не выявлено.

\section{Гидрогеохимические условия}

Обобщение ранее известной информации [14], а также гидродинамических и гидрогеохимических данных, полученных в 2012 г., свидетель- 
ствует о прямой гидродинамической зональности в разрезе исследуемой площади, с которой коррелируют гидрогеохимические зоны пресных и солоноватых вод.

Подземные воды зоны активного водообмена Нарыкско-Осташкинской площади по составу гидрокарбонатные кальциевые и кальциево-натриевые (рис. 2). Содержание иона $\mathrm{HCO}_{3}^{-}$изменяется от 0,32 до 0,58 г/л, но наиболее часто составляет 0,4 г/л, $\mathrm{Ca}^{2+}$ от 0,06 до 0,12 г/л, $\mathrm{Na}^{+}$в среднем до 0,03 г/л, а концентрации $\mathrm{Cl}^{-}$не превышает 0,024 г/л, в среднем составляет 0,006 г/л. С глубиной минерализация подземных вод увеличивается от 0,46 до 0,77 г/л. Одновременно с ростом минерализации растет и значение рН. Подземные воды в основном нейтральные, реже слабощелочные. Для подземных вод рассматриваемой площади наиболее характерны значения рН от 7,0 до 7,6.

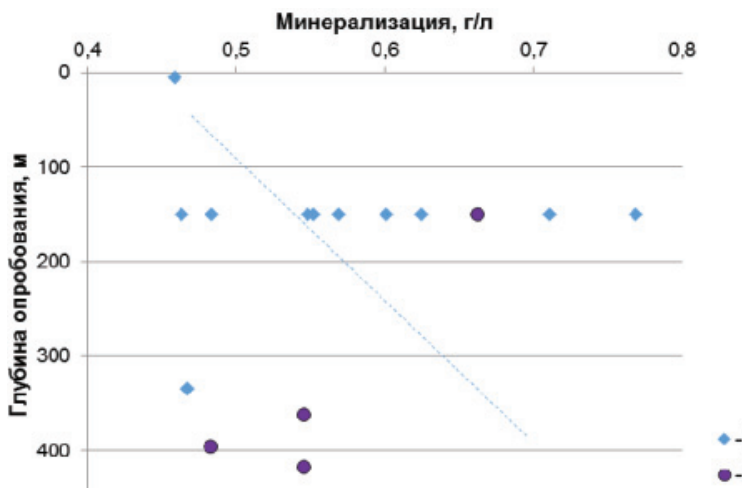

Рис. 2. Изменение минерализации подземных вод с глубиной в зоне активного водообмена. Типы вод по химическому составу: $1-\mathrm{HCO}_{3}-\mathrm{Ca} ; 2-\mathrm{HCO}_{3}-\mathrm{Ca}-\mathrm{Na}$

Fig. 2. Change of groundwater salinity by depth in the zone of active water exchange. Types of water are shown according to its chemical composition: $1-\mathrm{HCO}_{3}-\mathrm{Ca} ; 2-\mathrm{HCO}_{3}-\mathrm{Ca}-\mathrm{Na}$

Увеличение минерализации подземных вод происходит в основном за счет доли натрия в иснном составе. При этом, начиная с глубины порядка 350 м, наблюдаются воды гидрокарбонатного кальциево-натриевого состава. Таким образом, тип подземных вод меняется с гидрокарбонатного кальциевого на гидрокарбонатный кальциево-натриевый. Воды зоны активного водообмена в основном пресные, реже умеренно пресные.

Это объясняется тем, что с глубиной интенсивность водообмена снижается даже в пределах одной зоны, при этом возрастает время взаимодействия воды с горными породами, в результате чего в растворе происходит накопление элементов, что влечет за собой изменение их солености и щелочности.

Для зоны замедленного водообмена характерны достаточно сложные гидрогеохимические условия. Развитие этой зоны начинается с уменьшения распространения в разрезе продуктов выветривания и, как следствие, уменьшения интенсивности водообмена. В основном она заполнена гидрокарбонатными натриевыми (содовыми) водами.
По литературным данным известно, что в Кузбассе содовые воды развиты до глубины 1 км. По нашим данным они развиты шире, чем представлялось, и мы находим их на глубинах до 2 км, например, на ранее изученной соседней Талдинской площади, Березовоярском участке, в Томь-Усинском районе. На территории Нарыкско-Осташкинской площади они встречены до глубины 1 км, т. к. ниже данных по химическому опробованию пока нет.

Эти воды с минерализацией от 1 до 5-7 г/л (реже 0,5-0,8, 10-19 г/л) являются щелочными с $\mathrm{pH}$ от 8,0 (реже 7,5 ) до 10 , уже в верхней части гидродинамической зоны переходящие в гидрокарбонатные натриево-кальциевые, кальциево-натриевые (рис. 3,4$)$.

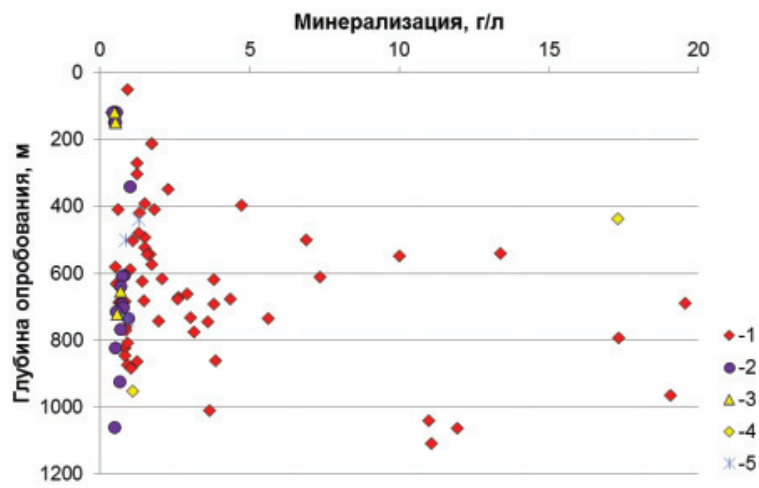

Рис. 3. Изменение минерализации вод зоны замедленного водообмена с глубиной. Типы вод по химическому составу: $1-\mathrm{HCO}_{3}-\mathrm{Na}$; $2-\mathrm{HCO}_{3}-\mathrm{Na}-\mathrm{Ca} ; 3-\mathrm{HCO}_{3}-\mathrm{Ca}-\mathrm{Na}$; $4-\mathrm{HCO}_{3}-\mathrm{Cl}-\mathrm{Na} ; 5-\mathrm{HCO}_{3}-\mathrm{SO}_{4}-\mathrm{Na}$

Fig. 3. Change of water mineralization in the zone of slow water exchange by depth. Types of water are shown according to its chemical composition: $1-\mathrm{HCO}_{3}-\mathrm{Na}$; $2-\mathrm{HCO}_{3}-\mathrm{Na}-\mathrm{Ca} ; 3-\mathrm{HCO}_{3}-\mathrm{Ca}-\mathrm{Na} ; 4-\mathrm{HCO}_{3}-\mathrm{Cl}-\mathrm{Na}$; $5-\mathrm{HCO}_{3}-\mathrm{SO}_{4}-\mathrm{Na}$

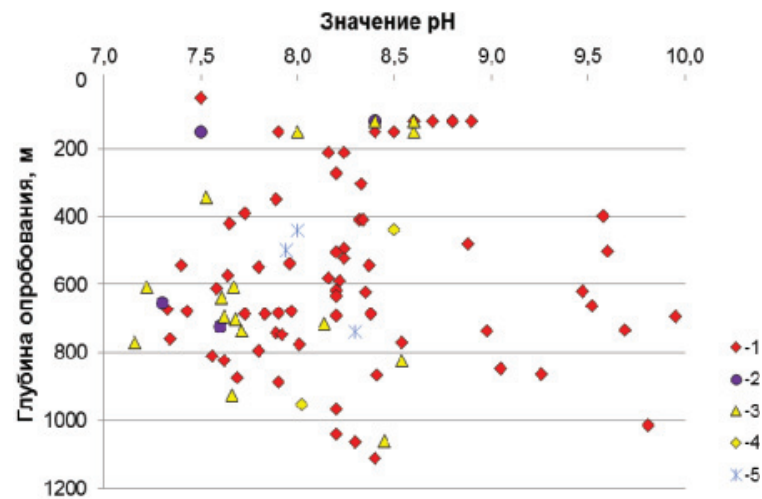

Рис. 4. Изменение значений рН вод зоны замедленного водообмена с глубиной. Типы вод по химическому составу: $1-\mathrm{HCO}_{3}-\mathrm{Na}$; $2-\mathrm{HCO}_{3}-\mathrm{Ca}-\mathrm{Na} ; 3-\mathrm{HCO}_{3}-\mathrm{Na}-\mathrm{Ca}$; $4-\mathrm{Cl}-\mathrm{HCO}_{3}-\mathrm{Na} ; 5-\mathrm{SO}_{4}-\mathrm{HCO}_{3}-\mathrm{Na}$

Fig. 4. Change of water $\mathrm{pH}$ values in the zone of slow water exchange by depth. Types of water are shown according to its chemical composition: $1-\mathrm{HCO}_{3}-\mathrm{Na} ; 2-\mathrm{HCO}_{3}-\mathrm{Ca}-\mathrm{Na}$; $3-\mathrm{HCO}_{3}-\mathrm{Na}-\mathrm{Ca} ; 4-\mathrm{Cl}-\mathrm{HCO}_{3}-\mathrm{Na} ; 5-\mathrm{SO}_{4}-\mathrm{HCO}_{3}-\mathrm{Na}$ 
Химический состав вод зоны замедленного водообмена определяется, в первую очередь, стадией взаимодействия воды с горными породами. Именно поэтому в ней увеличиваются, по сравнению с зоной активного водообмена, содержания $\mathrm{HCO}_{3}^{-}$от 0,3 до 5,3 г/л реже до $12,2-13,1$ г/л, $\mathrm{Na}^{+}$до 5,6 г/л и $\mathrm{Cl}^{-}$до 1,2 , реже до 2,9 г/л, тогда как $\mathrm{Ca}^{2+}$ уменьшается до 0,01 г/л. Практически все опробованные воды являются солоноватыми с минерализацией до 10 г/л, иногда слабосолеными (до 19,6 г/л). В составе водорастворенного газа преобладает метан (объемная доля составляет 85-95 \%).

Как уже было отмечено ранее, содовые воды в Кузбассе пользуются практически повсеместным распространением, начиная с глубин первых сотен метров $[1-6,9,15]$. При этом с глубиной содержание соды в них возрастает. Идентичную картину мы наблюдаем и на Нарыкско-Осташкинской площади (рис. 2, 3). Из приведенных рисунков видно, что с глубиной общая минерализация воды значительно возрастает. В основном этот рост обусловлен увеличением содержаний $\mathrm{HCO}_{3}^{-}$и $\mathrm{Na}^{+}$, тогда как содержание сульфат-иона в большинстве анализов не превышает 10 мг/л (реже до 70 мг/л), а хлора-иона - первые десятки мг/л. В то же время содержание в таких пробах $\mathrm{HCO}_{3}^{-}$намного выше и воды остаются гидрокарбонатными, реже - гидрокарбонатно-хлоридными, хлоридно-гидрокарбонатными и гидрокарбонатно-сульфатными.

Высокоминерализованные (слабосоленые) воды обогащены еще и рядом микрокомпонентов, например $\mathrm{Sr}, \mathrm{J}, \mathrm{Br}$. Эти и ряд других микрокомпонентов отмечаются для гидрокарбонатных натриевых вод с минерализацией 10-19 г/л и хлоридных натриевых вод (до 17 г/л) зоны замедленного водообмена, но в более низких концентрациях, чем характерны для зоны весьма замедленного водообмена. Однако содержание $\mathrm{Br}$ вполне сопоставимо с его содержаниями, установленными в Абашевской глубокой скважине, где в подземных водах с минерализацией 32-35 г/л концентрация $\mathrm{Br}$ составляет 9,5 и 43,3 мг/л соответственно [7]. В связи с этим можно предположить, что эти воды относятся к самым «низам» зоны замедленного водообмена.

Таким образом, отмеченные изменения в минерализации и $\mathrm{pH}$ подземных вод носят естественный характер и подчиняются прямой вертикальной зональности, которая свидетельствует об инфильтрационном генезисе изученных вод, а источником их восполнения являются атмосферные осадки, которые инфильтруются в водоносные комплексы из областей питания. По мере поступления воды на большую глубину соленость ее, как мы установили выше, растет, т. е. состав и величина общей минерализации подземных вод обусловлены временем взаимодействия воды с горной породой: чем медленнее она движется, тем длиннее ее путь, и соответственно, чем глубже она просачивается, тем выше соленость. Следовательно, величина общей минерализации и состав подземных вод определяются временем взаимодействия в системе вода-порода
[4]. Доказательств наличия глубинной составляющей в изученных водах в настоящее время не получено, и говорить о подтоке или вскрытии более глубоких вод пока оснований нет. Приведенные выше анализы подтверждают ранее сделанный вывод 0 том, что в пределах рассматриваемой структуры (Талдинской и Нарыкско-Осташкинской площадей) развиты инфильтрационные подземные воды, области питания которых располагаются на местных и отдаленных геоморфологически возвышенных, высокопроницаемых участках.

\section{Заключение}

Результаты выполненных исследований позволяют уточнить некоторые особенности гидрогеологических условий Нарыкско-Осташкинской площади. Так, по результатам опытно-фильтрационных работ в устье реки Осиновка установлено наличие гидравлической связи подземных вод верхней гидродинамической зоны с поверхностными водотоками, а также определены значения коэффициентов водопроводимости и уровнепроводности для этой части гидрогеологического разреза. На основе оценки взаимодействия подземных и поверхностных вод по результатам опытно-фильтрационных работ установлено наличие выраженного влияния граничных условий I и III рода на работу гидрогеологических скважин, что позволяет существенно актуализировать гидродинамические модели, которые могут быть использованы для обоснования добычи угольного метана в этом районе. Гидродинамическое опробование скважины у п. Чалток, в свою очередь, выявило этажное положение напоров подземных вод в толще пермских отложений при разнице уровней порядка 50 м и позволило определить фильтрационные характеристики двух опробованных толщ. Полученная информация уточняет ранее выдвигаемую рабочую гипотезу о единстве уровня подземных вод и тесной гидравлической связи всех водоносных зон в изучаемом районе. Созданы предпосылки для выделения относительно изолированных водоносных комплексов и горизонтов, по крайней мене в пределах распространения слаботрещиноватых массивов горных пород.

В целом гидродинамические условия Нарыкско-Осташкинской площади исследованы неравномерно как по площади, так и по глубине. В то же время общие закономерности строения центральной части Кузнецкого бассейна и распределения фильтрационных свойств пород в её пределах позволяют экстраполировать имеющиеся точечные данные на всю территорию исследуемой площади.

Данные гидрогеохимических опробований позволяют судить о корреляции гидродинамических и гидрогеохимических зон, что подтверждает зависимость состава подземных вод инфильтрационного генезиса от условий водообмена.

В изученном районе развиты разнообразные типы вод, которые подчиняются нормальной гидрогеохимической зональности, в соответствии с ко- 
торой можно выделить две гидрогеохимические зоны: пресных и солоноватых вод. Зона пресных вод соответствует зоне активного водообмена, которая характеризуется более высокой проницаемостью отложений. К этой зоне приурочены воды нейтральные и слабощелочные, пресные, гидрокарбонатного кальциевого состава. Зона замедленного водообмена - меньшей проницаемостью и развитием содовых вод $\left(\mathrm{HCO}_{3}-\mathrm{Na}\right)$ с минерализацией 0,5-19 г/л и рН от 7,5 до 9,9. В составе водорастворенного газа преобладает метан. Распространена зона замедленного водообмена на данной площади в основном в песчаных средне-верхнепермских отложениях, содержащих многочисленные угольные пласты.

В пределах зоны замедленного водообмена дополнительно можно выделить верхнюю и нижнюю части. Верхняя характеризуется наличием пресных или слабоминерализованных содовых вод (ми-

\section{СПИСОК ЛИТЕРАТУРЫ}

1. Нетрадиционные ресурсы метана угленосных толщ / Н.М. Сторонский, В.Т. Хрюкин, Д.В. Митронов, Е.В. Швачко // Рос. хим. ж. (Ж. Рос. хим. об-ва им. Д.И. Менделеева). - 2008. T. LII. - № 6. - C. 63-72.

2. Кузнецкий бассейн - крупнейшая сырьевая база промысловой добычи метана из угольных пластов / А.М. Карасевич, В.Т. Хрюкин, Б.М. Зимаков, Н.Г. Матвиенко, С.С. Золотых, В.Г. Натура, Т.С. Попова. - М.: Изд-во Академии горных наук, 2001. -64 c.

3. Гридасов А.Г. Результаты гидродинамических исследований структурной скважины № CH-15 на Чалтокском участке работ по поиску угольного метана (Кузбасс) // Проблемы геологии и освоения недр: Труды XVIII Международного симпозиума им. академика М.А. Усова студентов и молодых ученых. Т. І. Томск: Изд-во ТПУ, 2014. - С. 442-444.

4. Грицюк Я.М., Кочеткова В.М. Морфогеодинамическая томография угольных и углеметановых месторождений Кузбасса // Гидрогеология, инженерная гидрогеологния и гидроэкология: Материалы конференции, посвященной 75 летию кафедры ГИГЭ. - Томск, 2005. - С. 51-58.

5. Домрочева Е.В. Гидрогеохимические особенности угольных районов юга Кузбасса: автореф. дис. ... канд. геол.-минерал. наук. - Томск, 2005. - 22 c.

6. Домрочева Е.В., Лепокурова О.Е., Сизиков Д.А. Геохимическая характеристика подземных вод Нарыкско-Осташкинской площади (Кузбасс) // Известия Томского политехнического университета. - 2014. - Т. 325. - № 1. - С. 94-101.

7. Домрочева Е.В., Шварцев С.Л. Геохимия содовых вод Ерунаковского района Кузбасса // Гидрогеология и карстоведение. 2006. - Вып. 16. - С. 84-91.

8. Кусковский В.С., Кашеваров А.А., Рыбакова С.Т. Оценка запасов подземных вод инфильтрационных водозаборов (математическое моделирование). - Новосибирск: Изд-во СО РАН, 2004. $-156 \mathrm{c}$

9. Рогов Г.М., Попов В.К. Гидрогеология и катагенез пород Кузбасса. - Томск: Изд-во ТГУ, 1985. - 191 с

10. Токаренко О.Г. Подземные воды центральной части Кузбасса: химический состав в пределах различных ландшафтных областей // Известия Томского политехнического университета. 2012. - T. 321. - № 1. - С. 169-174.

11. Покровский Д.С. К вопросу режима подземных вод Ерунаковского района Кузбасса // Известия Томского политехнического института. - 1967. - Т. 167. - С. 32-35. нерализация 0,5-5 г/л), с повышенными концентрациями $\mathrm{Cl}^{-}$и иногда $\mathrm{SO}_{4}^{2-}$.

Нижняя часть зоны замедленного водообмена характеризуется наличием уже солоноватых и даже слабосоленых (минерализация до 19,6 г/л) содовых вод с повышенным содержанием $\mathrm{Cl}^{-}$, а также таких микрокомпонентов, как $\mathrm{Sr}, \mathrm{J}, \mathrm{Br} . \mathrm{B}$ составе водорастворенного газа продолжает накапливаться метан.

Рост минерализации вод с глубиной происходит в основном за счет ионов $\mathrm{HCO}_{3}^{-}$и $\mathrm{Na}^{+}$, реже за счет $\mathrm{SO}_{4}^{2-}$ (только в верхней части зоны замедленного водообмена) и $\mathrm{Cl}^{-}$ионов.

Выявленные закономерности изменения химического состав подземных вод по глубине подтверждают наличие двух гидродинамических зон в разрезе угленосной толщи и позволяют определять границу между ними с учетом выделенных типов подземных вод по химическому составу.

12. Покровский Д.С., Плевако Г.А. Гидрогеохимические условия зоны пологих брахиструктур Кузбасса на примере Ерунаковского угленосного района // Известия Томского политехнического института. - 1975. - Т. 297. - С. 57-63.

13. Геологическая эволюция и самоорганизация системы вода-порода: в 5 т. Т. 2: Система вода-порода в условиях зоны гипергенеза / С.Л. Шварцев, Б.Н. Рыженко, В.А. Алексеев, Е.М. Дутова, И.А. Кондратьева, Ю.Г. Копылова, О.Е. Лепокурова. - Новосибирск: Изд-во СО РАН, 2007. - 389 с.

14. Шварцев. С.Л., Домрочева Е.В., Рассказов Н.М. Геохимия формирования содовых вод Кузбасса // Известия Томского Политехнического Университета. - 2001. - Т. 318. - № 1. C. $128-134$.

15. Гидрогеология Ерунаковского района Кузбасса в связи с проблемой добычи угольного метана / С.Л. Шварцев, В.Т. Хрюкин, Е.В. Домрочева, К.И. Кузеванов, Н.М. Рассказов, Т.С. Попова, О.Е. Лепокурова, Е.В. Швачко // Геология и геофизика. - 2006. - Вып. 47. - № 7. - С. 878-889.

16. Гридасов А.Г., Кузеванов К.И. Схематизация гидрогеологических условий на участках добычи угольного метана в Кузбассе для обоснования прогнозных гидродинамических расчётов // Вестник Кузбасского государственного технического университета. - 2017. - № 3 (121). - С. 12-21.

17. Gridasov A.G., Kuzevanov K.I., Bogdanova A.G. Hydrogeological condition patterns of Kuznetsk Basin coalbed methane fields for estimating hydrodynamic calculations // IOP Conference Series: Earth and Environmental Science. - 2016. - V. 43. URL: http://iopscience.iop.org/article/10.1088/1755-1315/43/1/ 012022/pdf (дата обращения 20.04.2018).

18. Zhang X.L., Jing J.F., Hou Y.X., Liang B. Analysis on hydrogeology conditions of southern jingfang coal mine in Changzhi, Shanxi // Coal Geology of China- 2014. - V. 26. - P. 63-72.

19. Junliang G., Benjun L., Lai Y. Application of Water Chemistry and Isotope Analysis in the Coal Mine Hydrogeology Prospection // Hydrogeology. - 2014. - V. 1. - P. 38-45.

20. Post D. Impacts of Coal Seam Gas (Coal Bed Methane) Extraction on Water Resources in Australia // EGU General Assembly Conference Abstracts. - 2017. - V. 19. - P. 10861-10867.

21. Sun W., Zhou W., Jiao J. Hydrogeological classification and water inrush accidents in China's coal mines // Mine Water and the Environment. - 2016. - V. 35. - № 2. - P. 214-220.

22. Niec M. Evaluation of coal resources for underground gasification in Poland. Selection of possible UCG sites // Fuel. - 2017. V. 208. - P. 193-202. 
23. Jian L.I. Hydrogeological Characteristics of Inner Mongolia Dongsheng Coal Mine of Hongjingta / Sichuan Building Materials. - 2016. - V. 6. - P. 86-97.

24. Hou G.C. Hydrogeology of the Ordos basin, China // Journal of Groundwater Science and Engineering. - 2017. - V. 5. - № 2. P. 104-115.

25. Ge Y.Y. Characteristics of ion concentration in groundwater drainage from coalbed methane wells in Panzhuang of China // Electronic Journal of Geotechnical Engineering. - 2014. - V. 19. P. 3839-3849.

26. Yao Y., Liu D., Yan T. Geological and hydrogeological controls on the accumulation of coalbed methane in the Weibei field, southeastern Ordos Basin // International Journal of Coal Geology. 2014. - V. 121. - P. 148-159.

27. Meredith E.B. Coal aquifer contribution to streams in the Powder River Basin, Montana // Journal of Hydrology. - 2016. V. 537. - P. 130-137.
28. Owen D.D.R., Cox M.E. Hydrochemical evolution within a large alluvial groundwater resource overlying a shallow coal seam gas reservoir // Science of the Total Environment. - 2015. V. 523. - P. 233-252.

29. Sherwood 0.A. Groundwater methane in relation to oil and gas development and shallow coal seams in the Denver-Julesburg Basin of Colorado // Proceedings of the National Academy of Sciences. - 2016. - V. 113. - № 30. - P. 8391-8396.

30. Shvartsev S.L., Rasskazov N.M., Savichev 0.G. Contents and migration forms of elements in natural waters of the mid-Tom' basin // Geologiya i Geofizika. - 1997. - V. 38. - P. 1955-1961.

31. Rasskazov N.M., Savichev 0.G. Hydrogeochemical Conditions in Southeastern Western Siberia: the Evidence from the Tom River Basin // Environmental Geoscience. - 1999. - V. 2. - P. 120-129.

Поступила 01.06.2018 г.

\section{Информация об авторах}

Домрочева E.B., кандидат геолого-минералогических наук, научный сотрудник Томского филиала Института нефтегазовой геологии и геофизики им. А.А. Трофимука СО РАН.

$\boldsymbol{K}$ узеванов $\boldsymbol{K}$.И., кандидат геолого-минералогических наук, доцент отделения геологии инженерной школы природных ресурсов Национального исследовательского Томского политехнического университета.

Гридасов А.Г., ассистент отделения геологии инженерной школы природных ресурсов Национального исследовательского Томского политехнического университета.

Сизиков Д.А., заведующий лабораторией ОАО «Газпром промгаз» Научно-технического центра «Освоения нетрадиционных ресурсов углеводородов». 
UDC 556.3, 556.314

\title{
HYDROGEOLOGICAL CONDITIONS OF NARYK-OSTASHKIN AREA IN ERUNAKOVO REGION IN KUZBASS
}

\author{
Evgeniya V. Domrocheva',
}

DomrochevaYV@ipgg.sbras.ru

Konstantin I. Kuzevanov²,

kki@tpu.ru

\author{
Alexander G. Gridasov ${ }^{2}$ \\ gridasov@tpu.ru \\ Dmitry A. Sizikov \\ D.Sizikov@promgaz.gazprom.ru \\ ${ }^{1}$ Tomsk Branch of the Trofimuk Institute of Petroleum Geology and Geophysics of Siberian Branch of Russian Academy of Sci- \\ ences, \\ 4, Akademicheskiy Avenue, Tomsk, 634055, Russia. \\ 2 National Research Tomsk Polytechnic University, \\ 30, Lenin avenue, Tomsk, 634050, Russia. \\ ${ }^{3}$ Scientific-technical center "Development of unconventional hydrocarbon resources», \\ 6, Nametkin avenue, Moscow, 117420, Russia.
}

The relevance of the research is caused by the necessity of studying groundwater composition and hydrodynamic conditions at NarykOstashkin area of Kuzbass, promising for extraction of coal methane.

The main aim of the work is to characterize hydrodynamic conditions and hydrogeochemical features at Naryk-Ostashkin area, and to determine groundwater recharge and discharge conditions to provide base for hydrogeological generalization of coal bed methane mining perspective areas.

The methods. Chemical composition of groundwater and surface water was studied in the Problem research hydrogeochemical laboratory (TPU), registered in the system of analytical laboratories of Gosstandart of Russia. Traditional methods were used to conduct a complete chemical analysis. Processing of experimental-filtration works was performed by the standard graphic method of interim tracking the level with further graphic constructions and computations in the software package MS Office.

The results of the study allow clarifying some features of hydrogeological conditions of the Naryk-Ostashkin area. Thus, according to the results of experimental filtration work at the mouth of the river Osinovka, the authors have established the presence of hydraulic relation of groundwater of the upper hydrodynamic zone to the surface water currents, and determined the values of water supply and water level coefficients for this part of the hydrogeological section. Based on evaluation of underground and surface water interaction by the results of experimental filtration work, the real influence of boundary conditions of the I and III kind on hydrogeological well operation was established, that allows significantly updating the hydrodynamic models that can be used to justify the production of coal methane in this area. In addition, it was found out that within the massifs of slightly fractured rocks there are isolated pressure systems, the formation of which is caused by the presence of layers with low water supply in the section. The authors distinguished the zones of intensive and delayed water exchange by the nature of permeability in the hydrogeological section. Zones of fresh and brackish water correlate with hydrodynamical heterogeneity of rocks in hydrogeochemical relation.

Key words:

Groundwater, Kuzbass, Naryk-Ostashkin area, chemical composition, water genesis, hydrodynamic conditions

\section{REFERENCES}

1. Storonskiy N.M., Khryukin V.T., Mitronov D.V., Shvachko E.V. Unconventional resources of coal bed methane. Rus. chem. Journal, 2008, vol. LII, no. 6, pp. 63-72. In Rus.

2. Karasevich A.M., Khryukin V.T., Zimakov B.M., Matvienko N.G., Zolotyh S.S., Natura V.G., Popova T.S. Kuznetsky basseyn - krupneyshaya syryevaya baza dobychi metana iz ugolnykh plastov [Kuznetsk Basin is the largest base for methane extraction from coal seams]. Moscow, Mining Sciences Academy Publ. house, $2001.64 \mathrm{p}$.

3. Gridasov A.G. Rezultaty gidrodinamicheskikh issledovaniy strukturnoy skvazhiny № SN-15 na Chaltokskom uchastke rabot po poisku ugolnogo metana (Kuzbass) [Results of hydrodynamic investigations of structural well № SN-15 at Chalovsk area for searching for coal methane (Kuzbass)]. Problemy geologii i osvoeniya nedr. Trudy XVIII Mezhdunarodnogo simpoziuma imeni akademika M.A.Usova studentov i molodykh uchenykh [Problems of geology and exploration. Proc. Of the XVIII International simpozium named after academician M.A. Usov of students and young scientists]. Tomsk, TPU Publ. house, 2014. Vol. I, pp. 442-444.

4. Gritsyuk Ya.M., Kochetkova V.M. Morfogeodinamicheskaya tomografiya ugolnykh i uglemetanovykh mestorozhdeny Kuzbassa [Morphogeodynamic tomography of coal and coal-methane fields in Kuzbass]. Gidrogeologiya, inzhenernaya gidrogeologiya $i$ gidroekologiya. Materialy konferentsii, posvyashchennoy 75 letiyu kafedry GIGE [Hydrogeology, engineering hydrogeology and hydroecology. Proc. of the conference devoted to the $75^{\text {th }}$ anniversary of GIGE department]. Tomsk, 2005. pp. 51-58.

5. Domrocheva E.V. Gidrogeokhimicheskie osobennosti ugolnykh rayonov yuga Kuzbassa. Avtoreferat Dis. Kand. nauk [Hydroge- 
ochemical features of coal regions of Kuzbass coal. Cand. Dis. Abstract]. Tomsk, 2005. $22 \mathrm{p}$.

6. Domrocheva E.V., Lepokurova 0.E., Sizikov D.A. Geochemical characterization of underground water of the Naryksko-0stashkinskaya area (Kuzbass). Bulletin of the Tomsk Polytechnic University, 2014, vol. 325, no. 1, pp. 94-101. In Rus.

7. Domrocheva E.V., Shvartsev S.L. Geokhimiya sodovykh vod Erunakovskogo rayona Kuzbassa [Geochemistry of soda water of Erunakovsky region in Kuzbass]. Gidrogeologiya $i$ karstovedenie, 2006, Iss. 16, pp. 84-91.

8. Kuskovsky V.S., Kashevarov A.A., Rybakova S.T. Otsenka zapasov podzemnykh vod infiltratsionnykh vodozaborov (matematicheskoe modelirovanie) [Assessment of underground water resource in infiltration water supply inlet]. Novosibirsk, S0 RAN Press, 2004. $156 \mathrm{p}$.

9. Rogov G.M., Popov V.K. Gidrogeologiya i katagenez porod Kuzbassa [Hydrogeology and katagenesis of Kuzbass rocks]. Tomsk, TGU Press, $1985.191 \mathrm{p}$.

10. Tokarenko 0.G. Ground waters of Kuzbas central part: chemical composition within various landscape regions. Bulletin of the Tomsk Polytechnic University, 2012, vol. 321, no. 1, pp. 169-174. In Rus.

11. Pokrovsky D.S. K voprosu rezhima podzemnykh vod Erunakovskogo rayona Kuzbassa [On the issue of underground water mode in Erunaksky region in Kuzbas]. Izvestiya Tomskogo politekhnicheskogo instituta, 1967, vol. 167, pp. 32-35.

12. Pokrovskij D.S., Plevako G.A. Gidrogeokhimicheskie usloviya zony pologikh brakhistruktur Kuzbassa na primere Erunakovskogo uglenosnogo rayona [Hydrogeochemical conditions of the flat brachistructures area in Kuzbass coal-bearing region]. Izvestiya Tomskogo politekhnicheskogo instituta, 1975, vol. 297, pp. $57-63$.

13. Shvartsev S.L., Ryzhenko B.N., Alekseev V.A., Dutova E.M., Kondrateva I.A., Kopylova Yu.G., Lepokurova 0.E. Geologiches kaya evolyutsiya i samoorganizatsiya sistemy voda-poroda. T. 2. Sistema voda-poroda $v$ usloviyakh zony gipergeneza [Geological evolution and self-organization of water-rock system. Vol. 2. Water-rock system in hypergenesis]. Novosibirsk, S0 RAN Press, 2007. $389 \mathrm{p}$

14. Shvartsev S.L., Domrocheva E.V., Rasskazov N.M. Geochemistry and formation of Kuzbass soda waters. Bulletin of the Tomsk P0lytechnic University, 2001, vol. 318, no. 1, pp. 128-134. In Rus.

15. Shvartsev S.L., Khryukin V.T., Domrocheva E.V. Kuzevanov K.I., Passkazov N.M., Popova T.S., Lepokupova O.E., Shvachko E.V. Gidrogeologiya Erunakovskogo rayona Kuzbassa v svyazi s problemoy dobychi ugolnogo metana [Hydrogeology of the Erunakovo area of the Kuznetsk basin in the context of the problem of coal methane formation and mining]. Geologiya i geofizika, 2006, vol. 47 , pp. 878-889.

16. Gridasov A.G., Kuzevanov K.I. Generalisation of hydrogeological conditions at coalbed methane fields in the Kuznetsk coal basin for prediction hydrodynamic calculations. Vestnik Kuzbasskogo gosudarstvennogo tekhnicheskogo universiteta, 2017, no. 3, pp. 12-21. In Rus.
17. Gridasov A.G., Kuzevanov K.I., Bogdanova A.G. Hydrogeological condition patterns of Kuznetsk Basin coalbed methane fields for estimating hydrodynamic calculations. IOP Conference Series: Earth and Environmental Science, 2016, vol. 43. Available at: http://iopscience.iop.org/article/10.1088/1755-1315/ 43/1/012022/pdf (accessed 20 April 2018).

18. Zhang X.L., Jing J.F., Hou Y.X., Liang B. Analysis on hydrogeology conditions of southern jingfang coal mine in Changzhi, Shanxi. Coal Geology of China, 2014, vol. 26, pp. 63-72.

19. Junliang G., Benjun L., Lai Y. Application of Water Chemistry and Isotope Analysis in the Coal Mine Hydrogeology Prospection. Hydrogeology, 2014, vol. 1, pp. 38-45.

20. Post D. Impacts of Coal Seam Gas (Coal Bed Methane) Extraction on Water Resources in Australia. EGU General Assembly Conference Abstracts, 2017, vol. 19, pp. 10861-10867.

21. Sun W., Zhou W., Jiao J. Hydrogeological classification and water inrush accidents in China's coal mines. Mine Water and the Environment, 2016, vol. 35, no. 2, pp. 214-220.

22. Niec M. Evaluation of coal resources for underground gasification in Poland. Selection of possible UCG sites. Fuel, 2017, vol. 208, pp. 193-202.

23. Jian L.I. Hydrogeological Characteristics of Inner Mongolia Dongsheng Coal Mine of Hongjingta. Sichuan Building Materials, 2016, vol. 6, pp. 86-97.

24. Hou G.C. Hydrogeology of the Ordos basin, China. Journal of Groundwater Science and Engineering, 2017, vol. 5, no. 2, pp. 104-115.

25. Ge Y.Y. Characteristics of ion concentration in groundwater drainage from coalbed methane wells in Panzhuang of China. Electronic Journal of Geotechnical Engineering, 2014, vol. 19, pp. 3839-3849.

26. Yao Y., Liu D., Yan T. Geological and hydrogeological controls on the accumulation of coalbed methane in the Weibei field, southeastern Ordos Basin. International Journal of Coal Geology, 2014, vol. 121, pp. 148-159.

27. Meredith E.B. Coal aquifer contribution to streams in the Powder River Basin, Montana. Journal of Hydrology, 2016, vol. 537, pp. $130-137$.

28. Owen D.D.R., Cox M.E. Hydrochemical evolution within a large alluvial groundwater resource overlying a shallow coal seam gas reservoir. Science of the Total Environment, 2015, vol. 523, pp. 233-252.

29. Sherwood 0.A. Groundwater methane in relation to oil and gas development and shallow coal seams in the Denver-Julesburg Basin of Colorado. Proceedings of the National Academy of Sciences, 2016, vol. 113, no. 30, pp. 8391-8396.

30. Shvartsev S.L., Rasskazov N.M., Savichev 0.G. Contents and migration forms of elements in natural waters of the mid-Tom' basin. Geologiya i Geofizika, 1997, vol. 38, pp. 1955-1961.

31. Rasskazov N.M., Savichev 0.G. Hydrogeochemical Conditions in Southeastern Western Siberia: the Evidence from the Tom River Basin. Environmental Geoscience, 1999, vol. 2, pp. 120-129.

Received: 1 June 2018.

\section{Information about the authors}

Evgeniya V. Domrocheva, Cand. Sc., researcher, Tomsk Branch of the Trofimuk Institute of Petroleum Geology and Geophysics of Siberian Branch of Russian Academy of Sciences.

Konstantin I. Kuzevanov, Cand. Sc., associate professor, National Research Tomsk Polytechnic University.

Alexander G. Gridasov, assistant, National Research Tomsk Polytechnic University.

Dmitry A. Sizikov, head of the laboratory, Scientific-technical center «Development of unconventional hydrocarbon resources». 